\title{
Influence of Dissolving Fe-Nb-B-Dy Alloys in Zirconium on Phase Structure, Microstructure and Magnetic Properties
}

\author{
Grzegorz Ziółkowski ${ }^{1}$, Artur Chrobak ${ }^{1, *(\mathbb{D})}$, Ewa Talik ${ }^{1}$, Joanna Klimontko ${ }^{1}$ (i) and Dariusz Chrobak ${ }^{2}$ (1) \\ 1 Institute of Physics, University of Silesia in Katowice, 75 Pułku Piechoty 1A, 41-500 Chorzów, Poland; \\ grzegorz.ziolkowski@us.edu.pl (G.Z.); ewa.talik@us.edu.pl (E.T.); joanna.klimontko@us.edu.pl (J.K.) \\ 2 Institute of Materials Engineering, University of Silesia in Katowice, 75 Pułku Piechoty 1A, \\ 41-500 Chorzów, Poland; dariusz.chrobak@us.edu.pl \\ * Correspondence: artur.chrobak@us.edu.pl
}

Citation: Ziółkowski, G.; Chrobak A.; Talik, E.; Klimontko, J.; Chrobak, D. Influence of Dissolving $\mathrm{Fe}-\mathrm{Nb}-\mathrm{B}-\mathrm{Dy}$ Alloys in Zirconium on Phase Structure, Microstructure and Magnetic Properties. Materials 2021, 14, 2526. https://doi.org/10.3390/ ma14102526

Academic Editor: Antoni Planes

Received: 15 April 2021

Accepted: 9 May 2021

Published: 12 May 2021

Publisher's Note: MDPI stays neutral with regard to jurisdictional claims in published maps and institutional affiliations.

Copyright: (c) 2021 by the authors. Licensee MDPI, Basel, Switzerland. This article is an open access article distributed under the terms and conditions of the Creative Commons Attribution (CC BY) license (https:// creativecommons.org/licenses/by/ $4.0 /)$

\begin{abstract}
This paper refers to the structural and magnetic properties of $\left[\left(\mathrm{Fe}_{80} \mathrm{Nb}_{6} \mathrm{~B}_{14}\right)_{0.88} \mathrm{Dy}_{0.12}\right]_{1-\mathrm{x}} \mathrm{Zr}_{\mathrm{x}}$ $(x=0 ; 0.01 ; 0.02 ; 0.05 ; 0.1 ; 0.2 ; 0.3 ; 0.5)$ alloys obtained by the vacuum mold suction casting method. The analysis of the phase contribution indicated a change in the compositions of the alloys. For $x<0.05$, occurrence of the dominant $\mathrm{Dy}_{2} \mathrm{Fe}_{14} \mathrm{~B}$ phase was observed, while a further increase in the $\mathrm{Zr}$ content led to the increasing contribution of the Fe- $\mathrm{Zr}$ compounds and, simultaneously, separation of crystalline Dy. The dilution of $\left(\mathrm{Fe}_{80} \mathrm{Nb}_{6} \mathrm{~B}_{14}\right)_{0.88} \mathrm{Dy}_{0.12}$ in $\mathrm{Zr}$ strongly influenced the magnetization processes of the examined alloys. Generally, with the increasing $x$ parameter, we observed a decrease in coercivity; however, the unexpected increase in magnetic saturation and remanence for $x=0.2$ and $x=0.3$ was shown and discussed.
\end{abstract}

Keywords: hard magnetic materials; rare earth alloys; vacuum mold suction casting

\section{Introduction}

Searching for new magnetic materials is still of great importance, considering the continuing demand for their unique characteristics, which are required for a variety of applications [1-5]. This work refers to the so-called hard magnetic materials that are widely used in, for example, automotive or electric technologies. The main problem, as well as research direction, is to fill the gap between classical (e.g., ALNICO alloys [6,7]) and rare earth (RE) permanent magnets (e.g., $\mathrm{Nd}-\mathrm{Fe}-\mathrm{B}$ types of alloys [8-10]) by new magnetic systems without or with reduced RE content [11,12]. It seems that one possible way is to utilize magnetic composites containing magnetically hard (HM) and soft (SM) phases that can benefit from the high coercivity of the HM phase and high saturation of the SM phase [13-16]. In this approach, ultra-high coercive alloys are especially interesting considering the fact that the increasing contribution of the SM phase usually leads to a significant decrease in the resulting coercivity of the whole composite $[17,18]$. We reported the possibility of obtaining bulk alloys of $\mathrm{RE}-\mathrm{Fe}-\mathrm{Nb}-\mathrm{B}(\mathrm{RE}=\mathrm{Tb}, \mathrm{Dy})$ characterized by a more than $6 \mathrm{~T}$ coercive field at room temperature $[19,20]$. The key point for understanding this property lies in the specific microstructure of dendrite $\mathrm{RE}_{2} \mathrm{Fe}_{14} \mathrm{~B}$ grains achieved by a proper $\mathrm{Nb}$ concentration in combination with a high cooling rate, through the use of the mold suction casting technique. Unfortunately, the magnetic saturation is not particularly high due to the antiferromagnetic Fe-(Tb,Dy) coupling. However, this type of bulk alloy is a good candidate for the so-called spring-exchange composites as a source of magnetic anisotropy. It was confirmed that partial substitution of Tb by non-magnetic $\mathrm{Y}$ results in the formation of a bulk composite containing $\mathrm{Tb}_{2} \mathrm{Fe}_{14} \mathrm{~B}(\mathrm{HM})$ and $\mathrm{Y}_{2} \mathrm{Fe}_{14} \mathrm{~B}(\mathrm{SM})$ compounds with a similar dendrite microstructure [21]. In this case, $\mathrm{Y}$, with a similar atomic radius to $\mathrm{Tb}$, plays the same role but is non-magnetic. The achievement was a significant increase in magnetic remanence (about twofold) and the energy product $|\mathrm{BH}|_{\max }$ (about threefold). This suggested that further studies on other alloying additions for the RE-Fe- $\mathrm{Nb}-\mathrm{B}$ type 
of alloys can broaden knowledge about their impacts on phase composition as well as microstructure, both useful in assisting in the design of new hard magnetic materials.

The aim of this paper was to study the influence of dissolving the $\left(\mathrm{Fe}_{80} \mathrm{Nb}_{6} \mathrm{~B}_{14}\right)_{0.88} \mathrm{Dy}_{0.12}$ alloys in zirconium on phase structure, microstructure, and magnetic properties. Zirconium was chosen because it has a different (from Dy) atomic radius and forms compounds other than 2-14-1 with Fe. Thus, we expected significant changes in phase composition as well as microstructure that both influence final magnetic properties.

\section{Experimental Procedure}

The initial alloy of $\left(\mathrm{Fe}_{80} \mathrm{Nb}_{6} \mathrm{~B}_{14}\right)_{0.88} \mathrm{Dy}_{0.12}$ was obtained using typical arc-melting in a chamber with an argon atmosphere using commercially available basic elements (purity of 99.9\%). Next, the samples were crushed and mixed with a proper amount of $\mathrm{Zr}$, following the formula $\left[\left(\mathrm{Fe}_{80} \mathrm{Nb}_{6} \mathrm{~B}_{14}\right)_{0.88} \mathrm{Dy}_{0.12}\right]_{1-\mathrm{x}} \mathrm{Zr}_{\mathrm{x}}(x=0 ; 0.01 ; 0.02 ; 0.05 ; 0.1 ; 0.2 ; 0.3 ; 0.5)$. Such compositions were melted and crushed several times in order to ensure the homogeneity of the ingredients. The final step involved the application of the vacuum mold suction (described in detail in [22]), leading to obtaining the samples in the form of rods $1 \mathrm{~mm}$ in diameter and $3 \mathrm{~cm}$ in length.

The phase compositions of the samples were determined through the X-ray diffraction (XRD) technique. The XRD measurements were carried out using a high-resolution PANalytical Empyrean diffractometer (Malvern Panalytical, Malvern, UK) with $\mathrm{CuK} \alpha$ radiation (40 kV, $30 \mathrm{~mA}$ ) equipped with a PIXcel detector (Malvern Panalytical, Malvern, UK). The diffraction patterns were collected using a $2 \theta$ scan from 10 to $100^{\circ}$ with $0.0131^{\circ}$ steps. The data analysis was carried out using HighScore Plus software supplied by PANalytical (Version 4.9, Malvern Panalytical, Malvern, UK). The ICDD PDF-4 database was used to identify the phases.

The microstructure of the examined alloys was studied using a scanning electron microscope (SEM) JEOL JSM7600F (JEOL Ltd., Tokio, Japan) with an X-ray micro-probe. The samples were added to a conductive resin and polished in the following procedure. Preliminary grinding was carried out using a polishing machine (Metkon, Forcipol 102, Mettkon Instrunents Inc., Bursa, Turkey) and water-based abrasive papers (Klingspor, (Klingspor AG, Haiger, Germany) gradation successively: 220, 360, 600, 800, 1000, 1200, 1500). Next, polishing with diamond suspensions (Buehler (Waukegan, IL, USA) gradation: $6,3,1 \mu \mathrm{m})$ was applied. The finishing polishing was performed using a polishing cloth (Buehler, Waukegan, IL, USA) and colloidal suspension of silica with a grain size of $0.04 \mu \mathrm{m}$ (Struers, Cleveland, OH, USA). Pictures of the sample surface were collected using the back-scatter electron mode (BSE) showing contrasts of the differences in the mean atomic number between the individual points in the sample. The element maps were determined by means of the energy-dispersive X-ray spectrometry (EDX) option.

The magnetic measurements were carried out using the SQUID magnetometer (XL-7, Quantum Design, Quantum Desing, San Diego, CA, USA) in temperatures ranging from $2 \mathrm{~K}$ to $300 \mathrm{~K}$ and magnetic fields of $\pm 7 \mathrm{~T}$.

\section{Results and Discussion}

The phase structures of the examined alloys were determined using the XRD technique. As was expected, the relatively fast cooling rate during casting and the chemical composition of the alloys led to the formation of different binary and/or ternary compounds. Regarding the aim of this work, we focused on the phases that revealed magnetic properties. Figure 1 shows XRD patterns for all tested alloys and selected references for the most interesting magnetic phases. Table 1 quantitatively summarizes the contributions of these phases. 


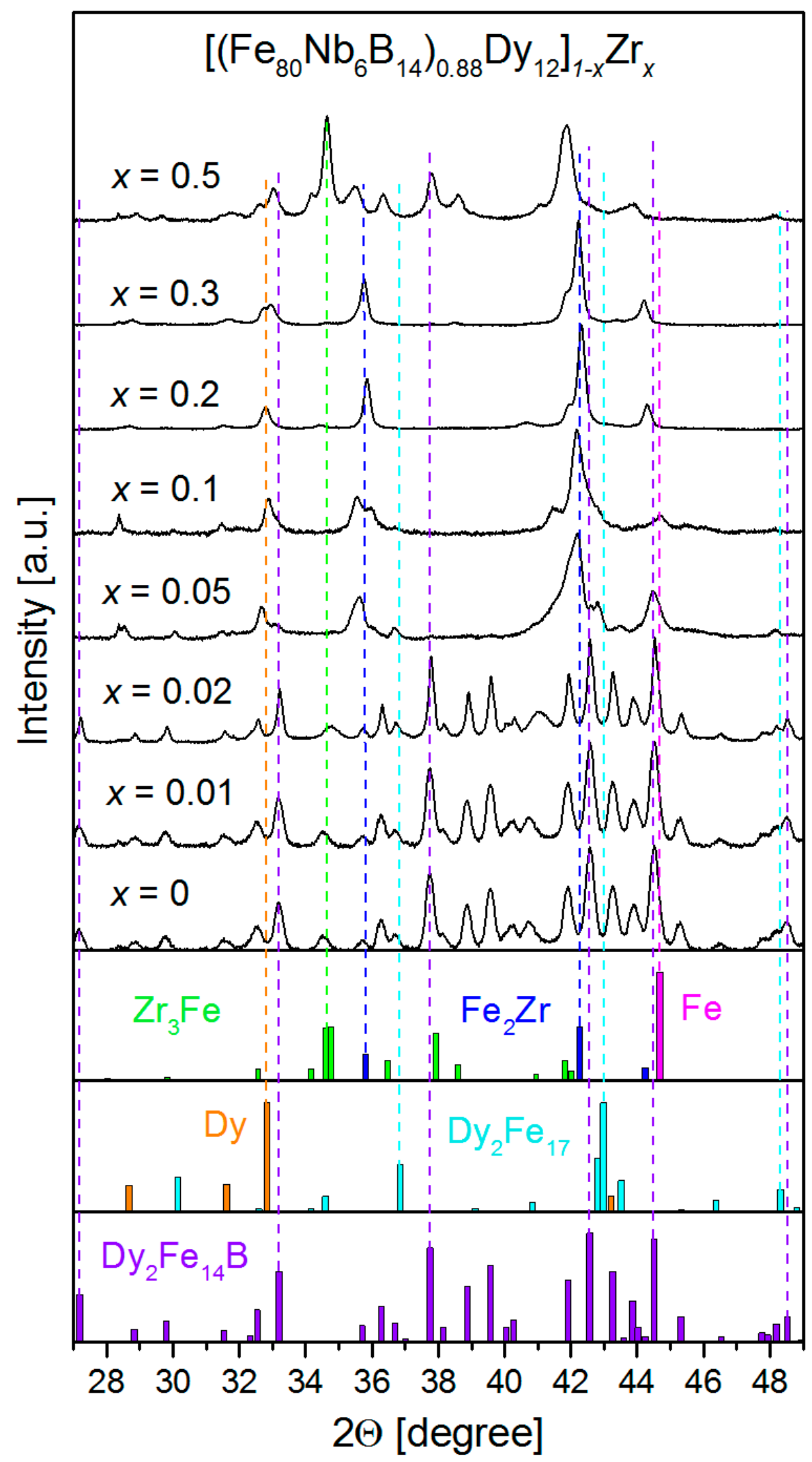

Figure 1. XRD patterns for all studied alloys and selected reference patterns for detected magnetic phases. 
Table 1. Contributions of these phases (at.\%) in $\left[\left(\mathrm{Fe}_{80} \mathrm{Nb}_{6} \mathrm{~B}_{14}\right)_{0.88} \mathrm{Dy}_{0.12}\right]_{1-\mathrm{x}} \mathrm{Zr}_{\mathrm{x}}$ determined from the XRD analysis. The estimated error of the phase content is about $2 \%$.

\begin{tabular}{cccccccc}
\hline $\mathbf{x}$ & $\mathbf{D y}_{\mathbf{2}} \mathbf{F e}_{\mathbf{1 4}} \mathbf{B}$ & $\mathbf{D y F e}_{\mathbf{2}}$ & $\mathbf{D y}_{\mathbf{2}} \mathrm{Fe}_{\mathbf{1 7}}$ & $\mathbf{D y}$ & $\mathbf{F e}_{\mathbf{2}} \mathbf{Z r}$ & $\mathbf{Z r}_{\mathbf{3}} \mathbf{F e}$ & $\mathbf{F e}$ \\
\hline 0 & 96 & 4 & - & - & - & - & - \\
0.01 & 96 & 4 & - & - & - & - & - \\
0.02 & 96 & 3 & - & - & - & - & - \\
0.05 & - & - & 23 & - & 15 & - & 14 \\
0.1 & - & - & - & 9 & 28 & - & 26 \\
0.2 & - & 4 & - & 10 & 76 & - & - \\
0.3 & - & 2 & - & 7 & 78 & - & - \\
0.5 & - & - & - & 7 & 11 & 60 & 3 \\
\hline
\end{tabular}

The alloys can be divided into two groups, i.e., containing $(x<0.05)$ and free $(x \geq 0.05)$ of the ternary $\mathrm{Dy}_{2} \mathrm{Fe}_{14} \mathrm{~B}$ compounds that are the main hard magnetic phase. For $x<0.05$, the contribution of this phase was high and was determined at the level of $96 \mathrm{wt} . \%$. Additionally, a 3-4 wt.\% content of $\mathrm{DyFe}_{2}$ (relatively soft magnetic) was detected. For the higher $\mathrm{Zr}$ concentration, the formation of $\mathrm{Fe}_{2} \mathrm{Zr}$ and $\mathrm{Zr}_{3} \mathrm{Fe}(x=0.5)$ together with separations of Dy and Fe was observed. It was interesting that while keeping the Fe-Dy ratio constant, the increasing presence of $\mathrm{Zr}$ significantly changed the phase structure. However, it seems that the preferred formation of the $\mathrm{Fe}-\mathrm{Zr}$ compounds leads to a relative deficiency of Fe for the synthesis of $\mathrm{Dy}_{2} \mathrm{Fe}_{14} \mathrm{~B}$. It should be emphasized that for $x>0.05$, the alloys are a kind of bulk composite, containing internally coupled (interacting), different magnetic phases of crystalline Dy and other soft magnetic Fe-Zr compounds. This fact can have an important meaning due to the high magnetic moment of $9 \mu_{\mathrm{B}}$ (where $\mu_{\mathrm{B}}$ is the Bohr magneton) attributed to the Dy atoms.

The microstructure of the studied alloys was determined by means of the SEM technique in the chemical contrast mode (back-scattered electrons). Figure 2 shows SEM pictures for selected alloy compositions. For the initial undiluted alloy $(x=0)$, the microstructure reveals micrometric dendrite grains that were expected and have been observed earlier elsewhere $[19,20]$. The presence of $2 \mathrm{wt} . \%$ of $\mathrm{Zr}$ caused partial fragmentation and smoothing of the grains, as shown in Figure $2 \mathrm{~b}$. The further increase in the $x$ parameter up to $10 \mathrm{wt} . \%$ led to the formation of needle-like grains with micrometric and even submicrometric sizes (in one dimension, see Figure 2c,d). The higher dissolution degree of the initial alloy (i.e., for $x \geq 20$ ) resulted in the growth of regular and relatively large grains.
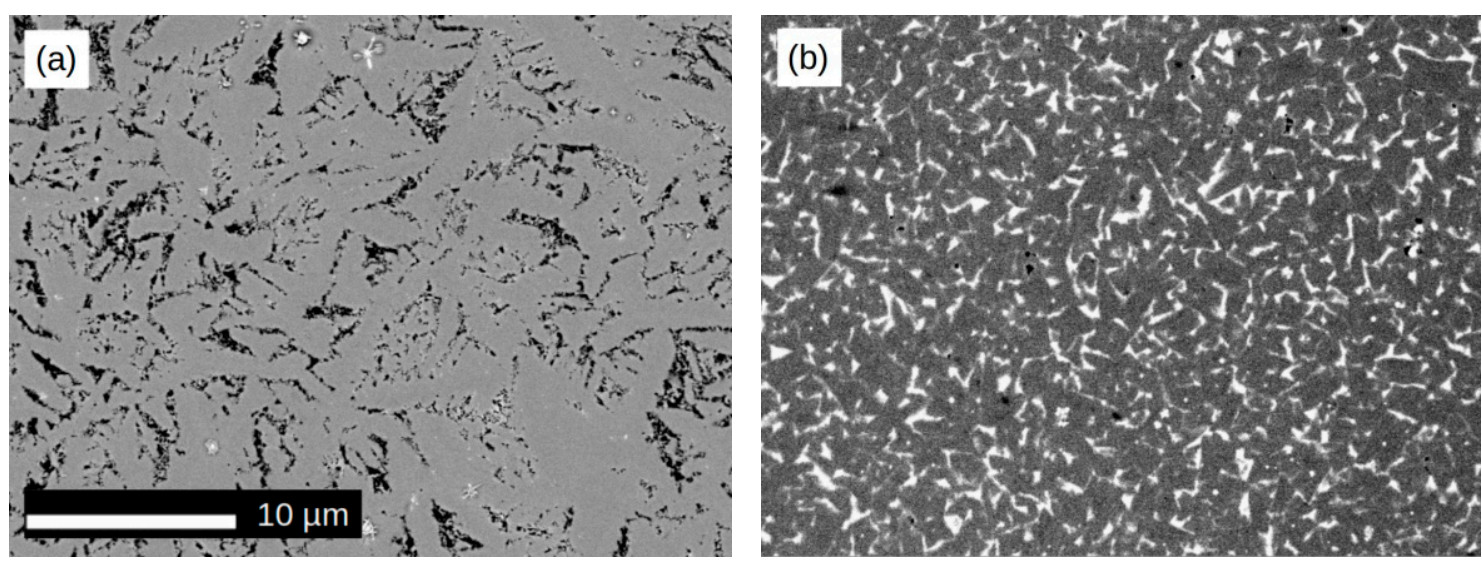

Figure 2. Cont. 

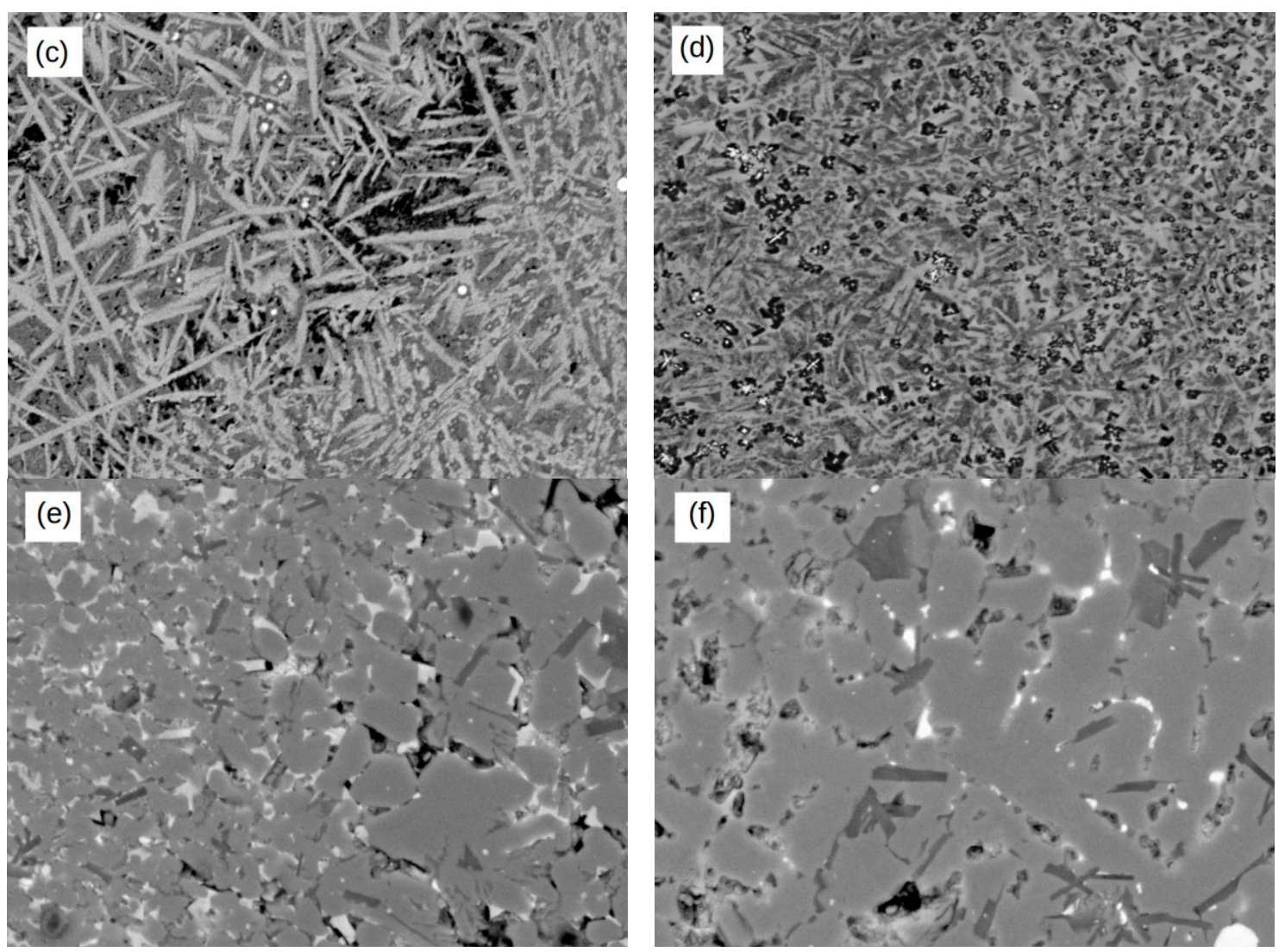

Figure 2. SEM images (BSE mode) for $\left[\left(\mathrm{Fe}_{80} \mathrm{Nb}_{6} \mathrm{~B}_{14}\right)_{0.88} \mathrm{Dy}_{0.12}\right]_{1-\mathrm{x}} \mathrm{Zr}_{\mathrm{x}} \cdot(\mathbf{a}) x=0$; (b) $x=0.02 ;$ (c) $x=0.05 ;(\mathbf{d}) x=0.1 ;(\mathbf{e}) x=0.2$; (f) $x=0.3$.

In order to show chemical compositions of the visible areas, element maps of Fe, Dy, $\mathrm{Zr}$, and $\mathrm{Nb}$ were determined using the SEM EDX technique. Figure 3 shows such element maps for the $\left[\left(\mathrm{Fe}_{80} \mathrm{Nb}_{6} \mathrm{~B}_{14}\right)_{0.88} \mathrm{Dy}_{0.12}\right]_{0.95} \mathrm{Zr}_{0.05}$ alloy. Taking into consideration that the location of the EDX analysis is about $2 \mu \mathrm{m}$, it can be stated that the Fe, Dy, and Zr elements were situated mainly in the needle-like grains, while $\mathrm{Nb}$ could be found in the area outside of these grains.
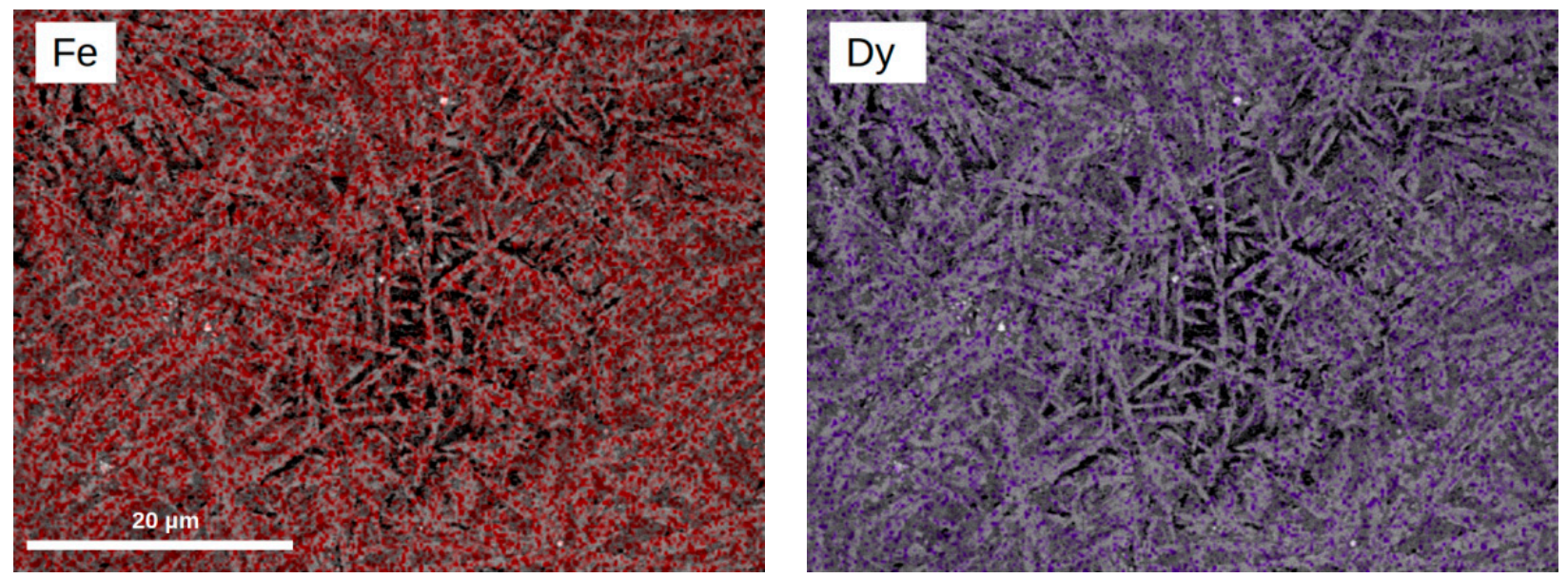

Figure 3. Cont. 

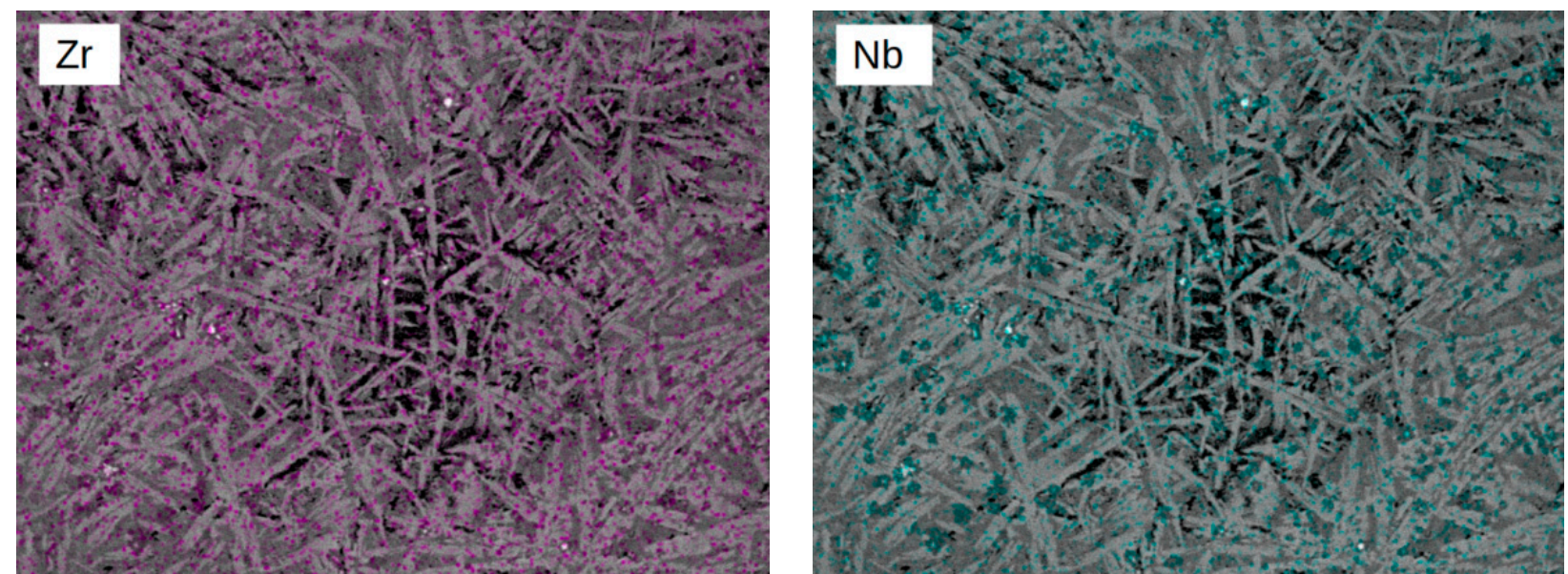

Figure 3. Maps of the selected elements for the $\left[\left(\mathrm{Fe}_{80} \mathrm{Nb}_{6} \mathrm{~B}_{14}\right)_{0.88} \mathrm{Dy}_{0.12}\right]_{0.95} \mathrm{Zr}_{0.05}$ alloy determined using the EDX technique.

The presented SEM observations lead to the conclusion that the dissolving of the $\left(\mathrm{Fe}_{80} \mathrm{Nb}_{6} \mathrm{~B}_{14}\right){ }_{0.88} \mathrm{Dy}_{0.12}$ alloy with zirconium results in remarkable changes of the microstructure. These changes should be discussed in terms of the phase structures determined by the XRD measurements. For $x \leq 2$, the alloys contain mainly the $\mathrm{Dy}_{2} \mathrm{Fe}_{14} \mathrm{~B}$ compound; however, the small amount of $\mathrm{Zr}$ influences crystal growth in the applied suction casting. Next, for $x=0.05$, one can observe a needle-like microstructure of the mainly hexagonal $\mathrm{Dy}_{2} \mathrm{Fe}_{17}$ phase, which was detected only in this case. The higher $\mathrm{Zr}$ concentration causes the formation of grains relatively larger and more regular in shape than mainly cubic Fe- $\mathrm{Zr}$ compounds.

Magnetic properties of the examined alloys were studied using the SQUID magnetometer. In order to demonstrate the magnetization processes, a set of magnetic hysteresis loops was measured at different temperatures ranging from $2 \mathrm{~K}$ to $300 \mathrm{~K}$. According to the phase structure changes (see Table 1), it is worth presenting the hysteresis separately for $0 \leq x \leq 0.05$ and for $0.05 \leq x \leq 0.5$. Figure 4 depicts full hysteresis loops for values of the $x$ parameter up to 0.05 , measured at $300 \mathrm{~K}$. As shown, the hysteresis loop for the initial undiluted alloy was strongly asymmetric and revealed ultra-high coercivity of about $5 \mathrm{~T}$ (in the second quadrant). It is important to take note that the so-called reverse magnetization process occurs in two steps: the first in $\mu_{0} H \approx 0$, and the second in $\mu_{0} H \approx-5 \mathrm{~T}$. The low concentration of $\operatorname{Zr}(x=0.01, x=0.02)$ caused a decrease in the coercive field; additionally, the hysteresis loops were symmetric. The further increase in the $\mathrm{Zr}$ content $(x=0.05)$ resulted in a collapse of coercivity and a decrease in magnetic saturation. Figure 5 shows magnetic hysteresis loops for the alloys with $x \geq 0.05$. A subsequent decrease in coercivity (with increasing $x$ ) and non-monotonic changes of magnetic saturation can be observed. The magnetic characteristics at lower temperatures (see Figure 6 for $\mathrm{T}=2 \mathrm{~K}$ ) are particularly interesting because magnetization processes are a competition between different kinds of energies, including magnetostatic, exchange, anisotropy, and thermal energies. In the case of the alloys containing the hard magnetic $\mathrm{Dy}_{2} \mathrm{Fe}_{14} \mathrm{~B}$ phase, the low temperatures resulted in domination of the anisotropy energy and, applying the maximum external magnetic field available in our apparatus of $\pm 7 \mathrm{~T}$, the material could not be magnetically saturated. The hysteresis was strongly asymmetric, which apparently decreased the measured defined coercive fields. On the other hand, for the alloys containing separations of Dy (the Curie point equal to $92 \mathrm{~K}$ ), one can expect a significant contribution of this element regarding its high atomic magnetic moment. 


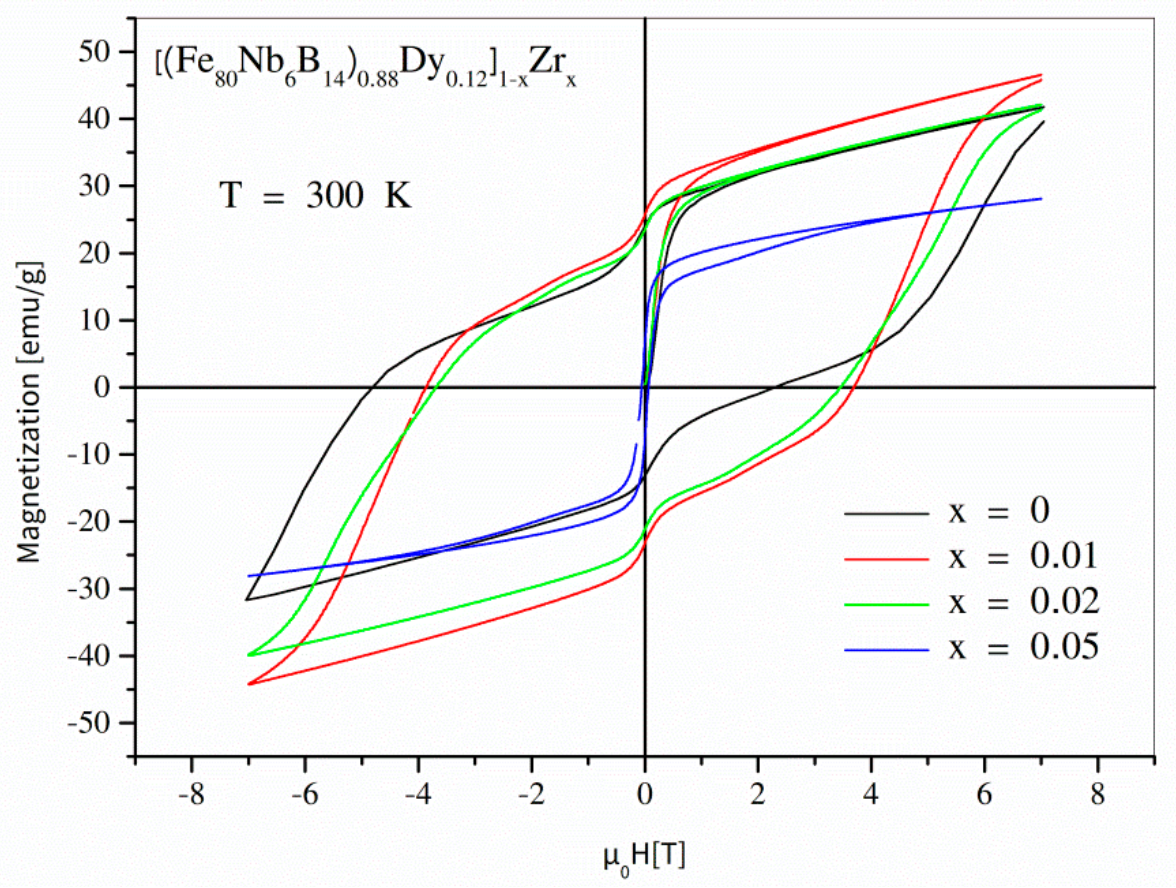

Figure 4. Hysteresis loops for the $\left[\left(\mathrm{Fe}_{80} \mathrm{Nb}_{6} \mathrm{~B}_{14}\right)_{0.88} \mathrm{Dy}_{0.12}\right]_{1-\mathrm{x}} \mathrm{Zr}_{\mathrm{x}}(0 \leq x \leq 0.05)$ alloys measured at room temperature.

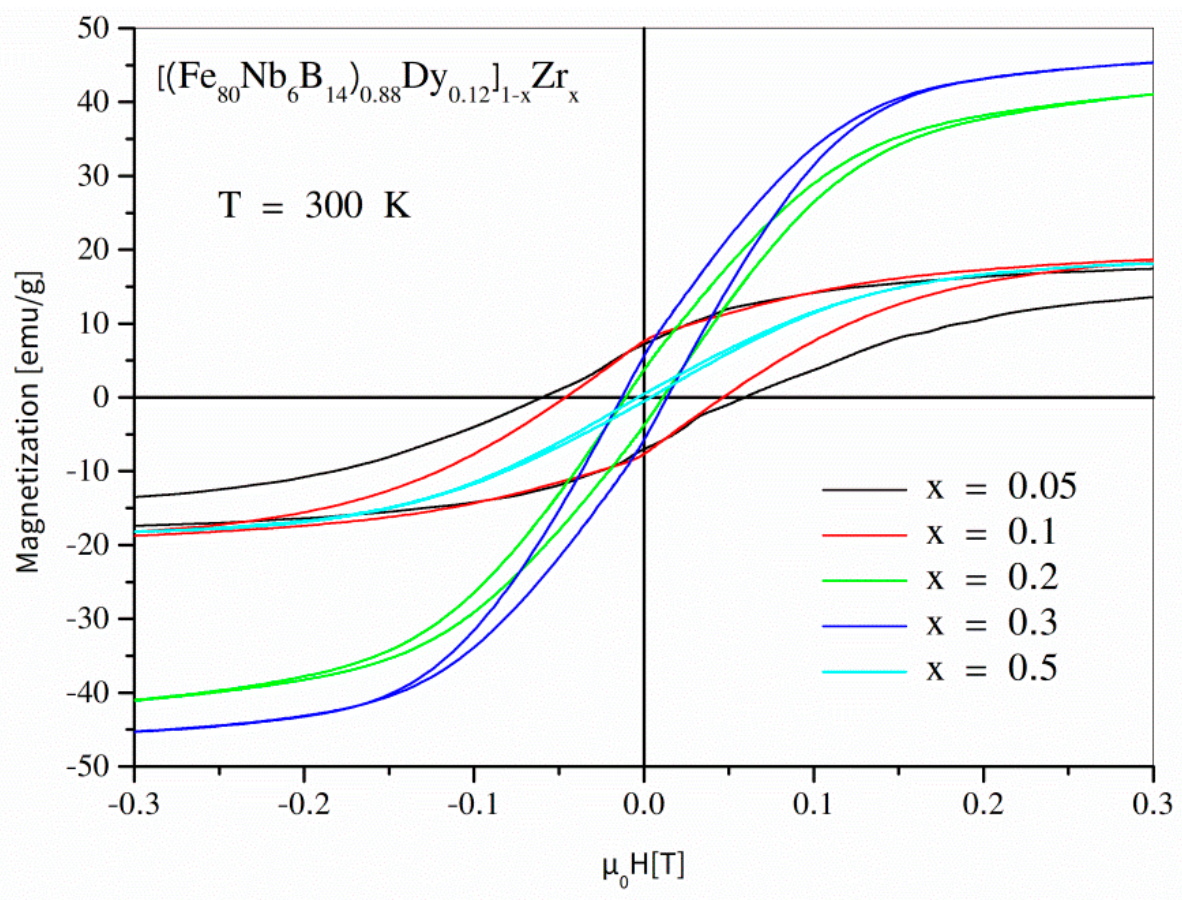

Figure 5. Hysteresis loops for the $\left[\left(\mathrm{Fe}_{80} \mathrm{Nb}_{6} \mathrm{~B}_{14}\right)_{0.88} \mathrm{Dy}_{0.12}\right]_{1-\mathrm{x}} \mathrm{Zr}_{\mathrm{x}}(0.05 \leq x \leq 0.5)$ alloys measured at room temperature. 


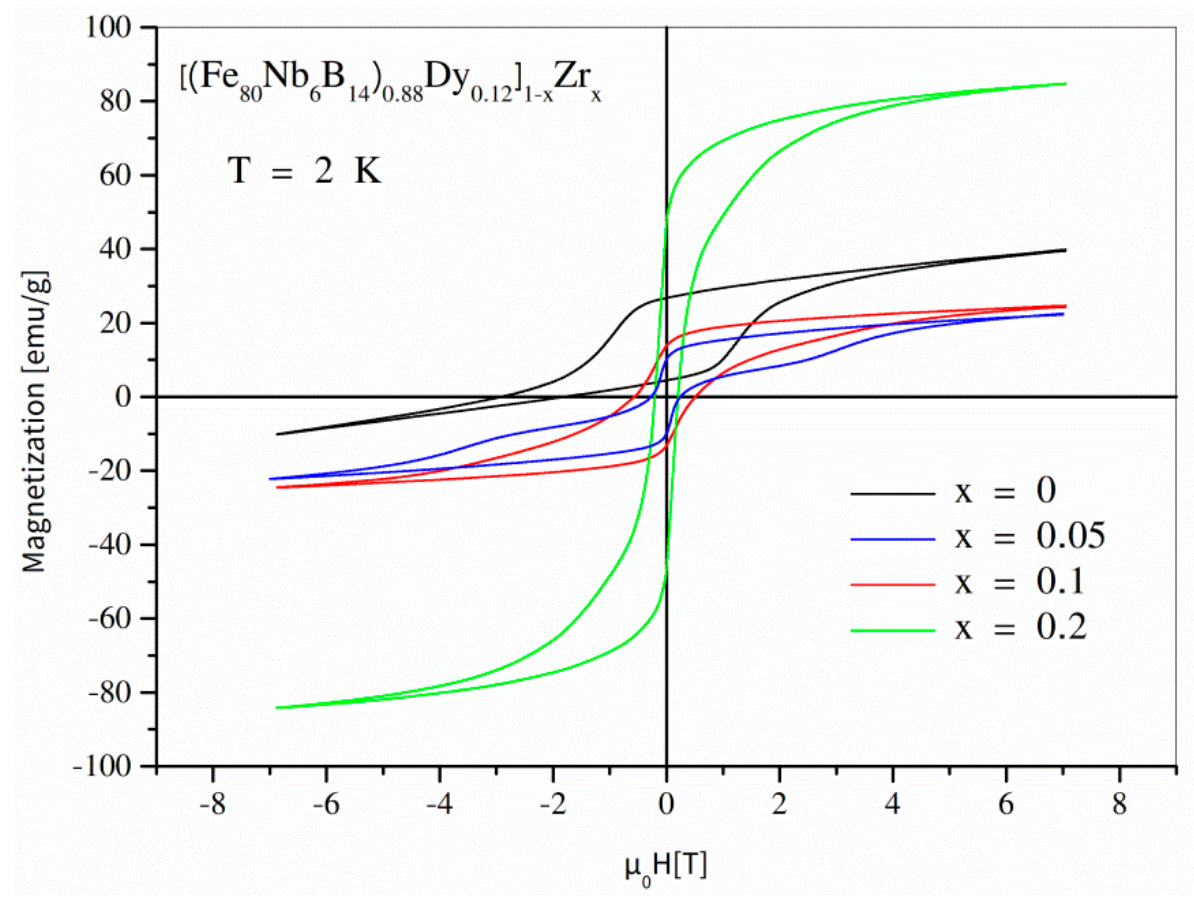

Figure 6. Hysteresis loops for selected $\left[\left(\mathrm{Fe}_{80} \mathrm{Nb}_{6} \mathrm{~B}_{14}\right)_{0.88} \mathrm{Dy}_{0.12}\right]_{1-\mathrm{x}} \mathrm{Zr}_{\mathrm{x}}$ alloys measured at a low temperature of $2 \mathrm{~K}$.

The values of coercive field $H_{\mathrm{c}}$, magnetic saturation $M_{\mathrm{s}}$, as well as magnetic remanence $M_{\mathrm{r}}$ for all tested temperatures are displayed in Table 2. For comparison, Figures 7 and 8 $\left(H_{\mathrm{c}}\right)$ and $\left(M_{\mathrm{s}}\right.$ and $\left.M_{\mathrm{r}}\right)$ show these values as a function of the $x$ parameter for $\mathrm{T}=300 \mathrm{~K}$ and $\mathrm{T}=2 \mathrm{~K}$. Generally, the disappearance of the hard magnetic $\mathrm{Dy}_{2} \mathrm{Fe}_{14} \mathrm{~B}$ phase caused the collapse of $H_{\mathrm{c}}$, especially at room temperature. However, it is quite surprising that the low-temperature measurements revealed non-zero (even more than $0.5 \mathrm{~T}$ ) coercivity for the alloys free of the hard magnetic $\mathrm{Dy}_{2} \mathrm{Fe}_{14} \mathrm{~B}$ and $\mathrm{Dy}_{2} \mathrm{Fe}_{17}$ phases, i.e., for $x \geq 0.1$. Most likely, the anisotropy originated from the interphase regions where some Dy-Fe disordered phases can occur and influence magnetization processes via exchange interactions.

Table 2. Coercive field $H_{\mathrm{c}}$, magnetic saturation $M_{\mathrm{s}}$ as well as magnetic remanence $M_{\mathrm{r}}$ for all tested alloys determined from hysteresis loops measured at different temperatures. The errors of the listed values are in the level of the last printed digit.

\begin{tabular}{|c|c|c|c|c|c|c|c|c|c|c|c|c|c|c|c|}
\hline \multirow{2}{*}{$x$} & \multicolumn{5}{|c|}{$\mu_{0} H_{c}(\mathrm{~T})$} & \multicolumn{5}{|c|}{$M_{\mathrm{s}}(\mathrm{emu} / \mathrm{g})$} & \multicolumn{5}{|c|}{$M_{\mathrm{r}}(\mathrm{emu} / \mathrm{g})$} \\
\hline & $300 \mathrm{~K}$ & $200 \mathrm{~K}$ & $100 \mathrm{~K}$ & $10 \mathrm{~K}$ & $2 \mathrm{~K}$ & $300 \mathrm{~K}$ & $200 \mathrm{~K}$ & $100 \mathrm{~K}$ & $10 \mathrm{~K}$ & $2 \mathrm{~K}$ & $300 \mathrm{~K}$ & $200 \mathrm{~K}$ & $100 \mathrm{~K}$ & $10 \mathrm{~K}$ & $2 \mathrm{~K}$ \\
\hline 0 & 4.79 & - & - & - & - & 41.08 & 38.40 & 38.83 & 39.85 & 39.97 & 24.15 & 22.90 & 25.44 & 26.78 & 27.10 \\
\hline 0.01 & 3.83 & 5.56 & - & - & - & 46.12 & 43.02 & 42.12 & 42.66 & 42.82 & 25.86 & 24.46 & 24.95 & 27.60 & 29.84 \\
\hline 0.02 & 3.70 & 5.19 & - & - & - & 42.15 & 39.30 & 38.45 & 28.2 & 38.04 & 23.62 & 22.19 & 23.09 & 25.24 & 24.95 \\
\hline 0.05 & 0.06 & 0.07 & 0.13 & 0.27 & 0.31 & 28.14 & 25.38 & 25.22 & 23.37 & 22.28 & 7.16 & 6.85 & 7.74 & 10.03 & 11.18 \\
\hline 0.1 & 0.04 & 0.1 & 0.19 & 0.56 & 0.54 & 27.56 & 23.46 & 22.96 & 25.04 & 24.87 & 8.12 & 8.65 & 9.19 & 13.70 & 13.75 \\
\hline 0.2 & 0.01 & 0.02 & 0.05 & 0.16 & 0.20 & 51.41 & 63.34 & 79.50 & 84.78 & 84.92 & 3.56 & 8.53 & 19.34 & 43.35 & 47.38 \\
\hline 0.3 & 0.01 & 0.02 & 0.04 & 0.09 & 0.10 & 53.17 & 64.32 & 83.25 & 91.54 & 92.16 & 5.76 & 10.28 & 20.47 & 44.71 & 46.94 \\
\hline 0.5 & 0.004 & 0.005 & 0.012 & 0.031 & 0.038 & 22.89 & 29.31 & 41.43 & 48.83 & 49.13 & 0.53 & 0.79 & 1.88 & 5.15 & 6.20 \\
\hline
\end{tabular}




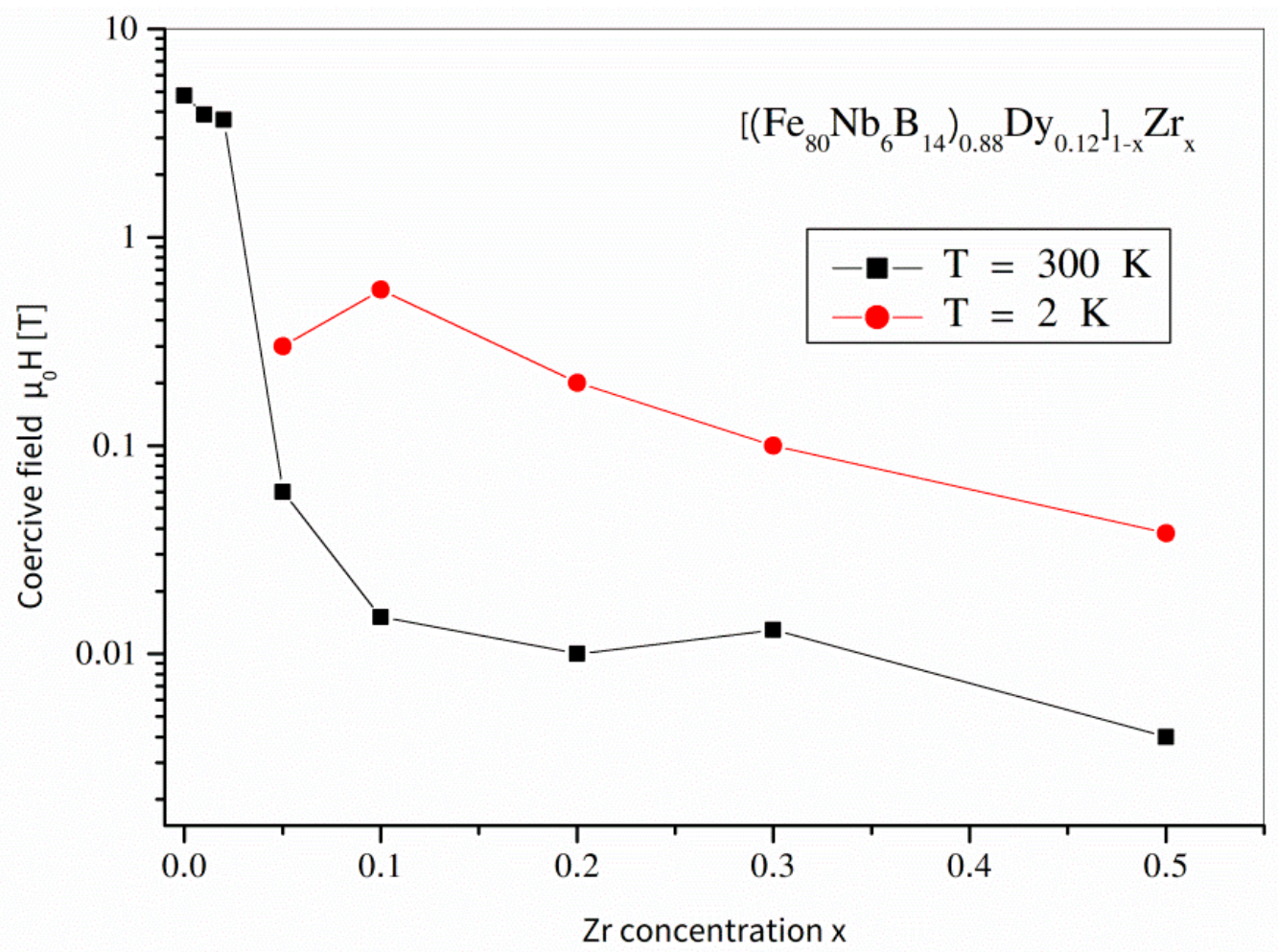

Figure 7. Coercive field $H_{\mathrm{C}}$ for the $\left[\left(\mathrm{Fe}_{80} \mathrm{Nb}_{6} \mathrm{~B}_{14}\right)_{0.88} \mathrm{Dy}_{0.12}\right]_{1-\mathrm{x}} \mathrm{Zr}_{\mathrm{x}}(0 \leq x \leq 0.5)$ alloys determined at $300 \mathrm{~K}$ and $2 \mathrm{~K}$.

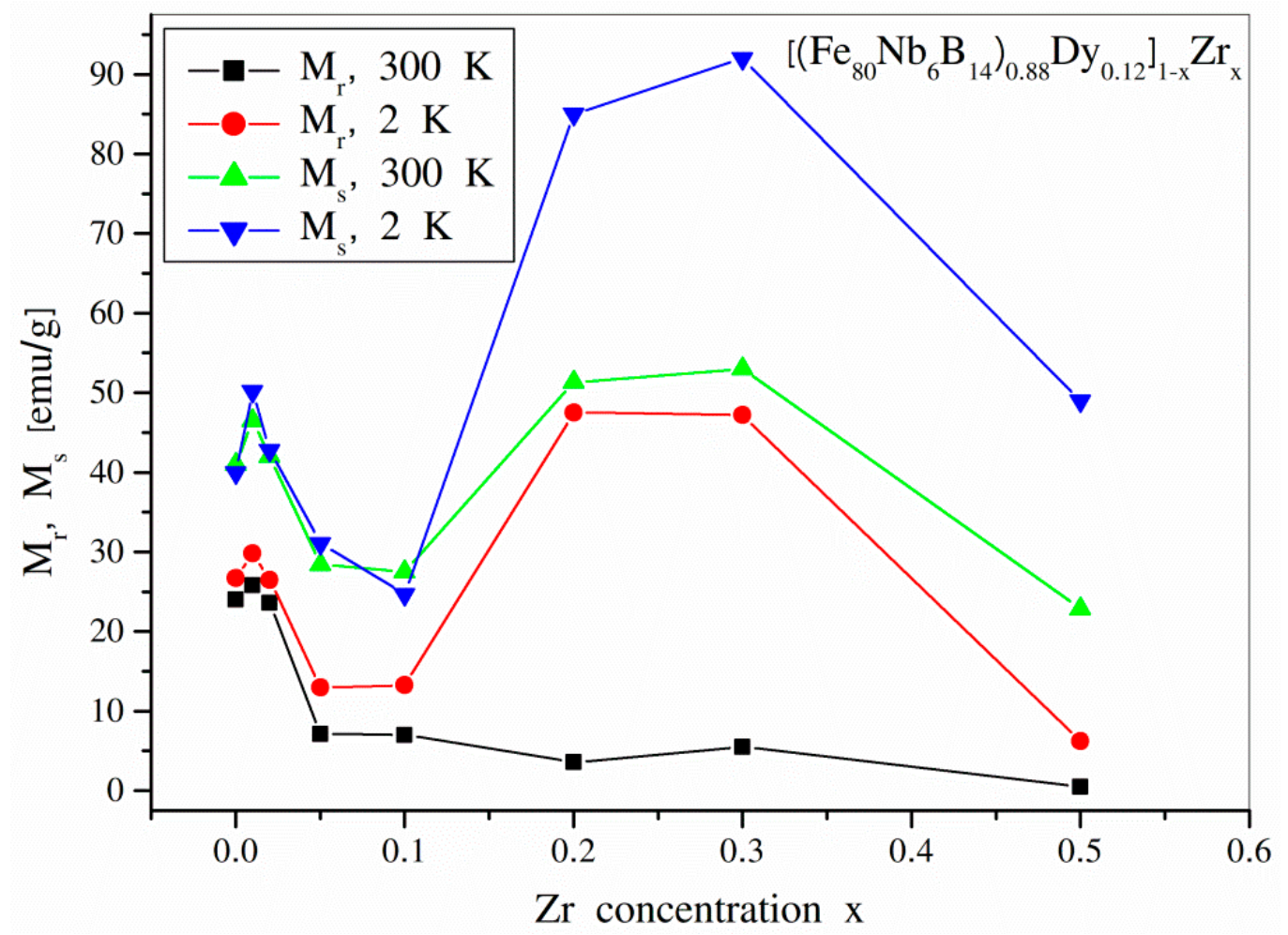

Figure 8. Magnetic saturation $M_{\mathrm{s}}$ and magnetic remanence $M_{\mathrm{r}}$ for the $\left[\left(\mathrm{Fe}_{80} \mathrm{Nb}_{6} \mathrm{~B}_{14}\right)_{0.88} \mathrm{Dy}_{0.12}\right]_{1-\mathrm{x}} \mathrm{Zr}_{\mathrm{x}}$ $(0 \leq x \leq 0.5)$ alloys determined at $300 \mathrm{~K}$ and $2 \mathrm{~K}$.

The changes of $M_{\mathrm{s}}$ and $M_{\mathrm{r}}$ as a function of the dissolution degree are also surprising. Following the increasing $x$ parameter, $1 \mathrm{wt} . \%$ of $\mathrm{Zr}$ caused an increase in both parameters. 
Next, up to $x=0.1$, one can observe a decrease in $M_{\mathrm{s}}$ and $M_{\mathrm{r}}$. The highest values of the analyzed quantities were noticed for $x=0.2$ and $x=0.3$. This effect can be explained based on the changing phase structure and the fact that magnetic moments of Dy and Fe in compounds are coupled antiferromagnetically. Exemplary for the $\mathrm{Dy}_{2} \mathrm{Fe}_{14} \mathrm{~B}$, the magnetic moment per formula unit can be estimated as $14 \mu_{\mathrm{Fe}}-2 \mu_{\mathrm{Dy}} \approx 28 \mu_{\mathrm{B}}-18 \mu_{\mathrm{B}}-10 \mu_{\mathrm{B}}$. This means that the average magnetic moment calculated per Fe atom is $0.71 \mu_{\mathrm{B}}$. In contrast, for $\mathrm{Fe}_{2} \mathrm{Zr}$, the average magnetic moment per $\mathrm{Fe}$ atom equals about $2 \mu_{\mathrm{B}}$. Therefore, the changing phase composition of the tested alloys can result in the observed increase in $M_{\mathrm{S}}$, even though increasing the $x$ parameter means dissolution of the magnetic compound in non-magnetic Zr. Additionally, magnetic saturation and remanence are enhanced by the crystalline Dy when the temperature is below its Curie point.

Let us analyze the impact of the $\mathrm{Zr}$ addition for the alloys containing the hard magnetic $\mathrm{Dy}_{2} \mathrm{Fe}_{14} \mathrm{~B}$ phase. Generally, the hysteresis loops for these alloys are not magnetically uniform, i.e., the reverse magnetization curve (the first and the second quadrant) reveals more than one maximum of $\mathrm{d} M / \mathrm{d} H$ dependence. In the case of a material containing different magnetic phases/objects (uncoupled or not perfectly coupled) with different anisotropies, one can expect an occurrence of many magnetization speed maxima in different magnetic fields related to anisotropy fields of the phases. Figure 9 shows the $\mathrm{d} M / \mathrm{d} H$ dependencies for $x \leq 0.05$. In all cases, a soft magnetic phase is visible as a peak with the maximum placed at $H=0$. For $x=0$, there is a hard magnetic component with a maximum remagnetization speed of about $6 \mathrm{~T}$. The addition of $1 \mathrm{wt} . \%$ of $\mathrm{Zr}$ leads to a shift of this maximum into lower fields as well as an appearance of the additional component at $\mu_{0} H=1.8 \mathrm{~T}$. A more complex structure of magnetic objects reveals the alloys with $2 \mathrm{wt} . \%$ of $\mathrm{Zr}$. Four components can be observed: soft magnetic at $H=0$ as well as hard magnetic at $5.5 \mathrm{~T}, 4 \mathrm{~T}$, and $1.8 \mathrm{~T}$. According to this information, the phase structure is almost the same for $x<0.05$, and the detected differences should be attributed to a changing distribution of $\mathrm{Dy}_{2} \mathrm{Fe}_{14} \mathrm{~B}$ grains. This conclusion is in agreement with our previous simulation research, when a lowering of the anisotropy field with decreasing grain size was shown. In this variety of the $x$ parameter, the SEM observations also indicated lowering of the grain size as a function of the increasing $\mathrm{Zr}$ addition.

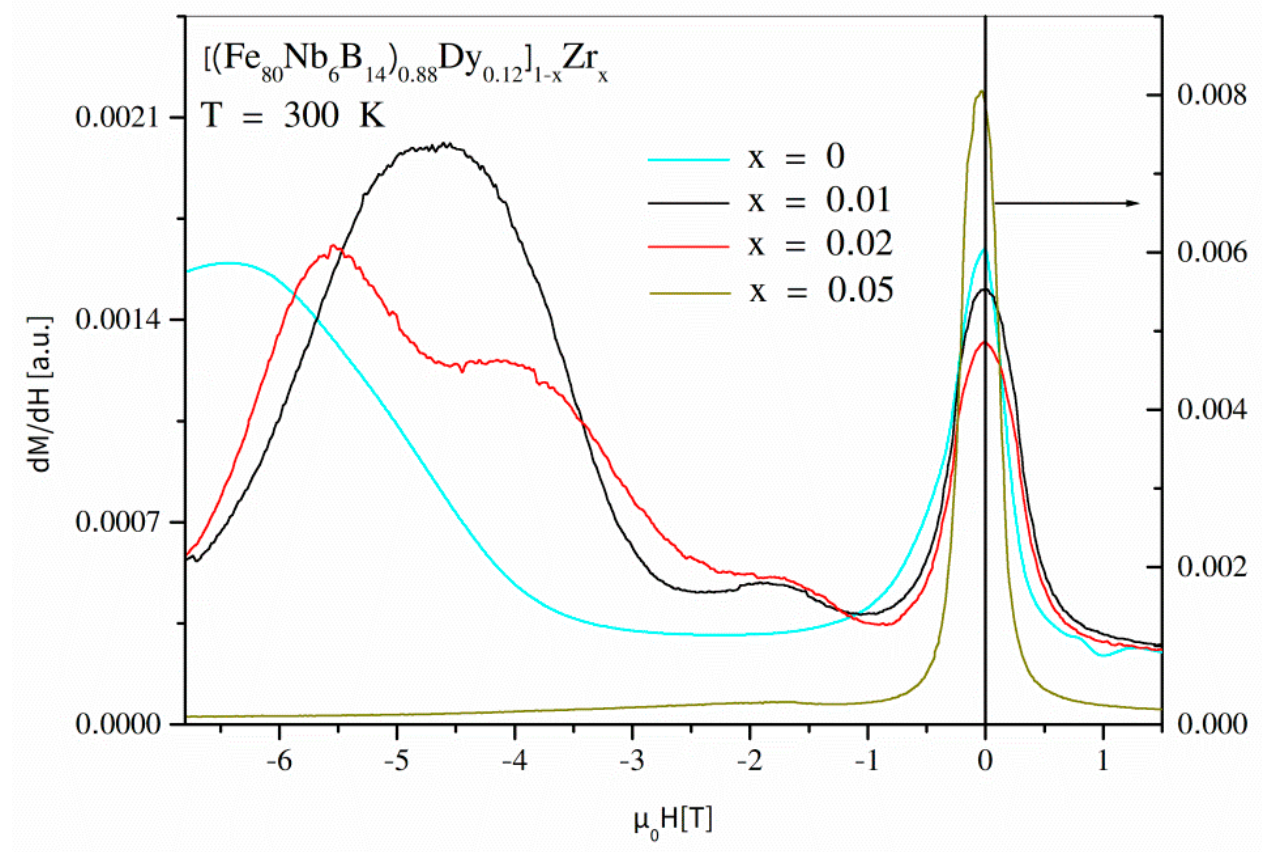

Figure 9. $\mathrm{d} M / \mathrm{d} H$ dependencies for the $\left[\left(\mathrm{Fe}_{80} \mathrm{Nb}_{6} \mathrm{~B}_{14}\right)_{0.88} \mathrm{Dy}_{0.12}\right]_{1-\mathrm{x}} \mathrm{Zr}_{\mathrm{x}}(0 \leq x \leq 0.5)$ alloys determined at $300 \mathrm{~K}$. 
In summary, it can be stated that the influence of dissolving $\left(\mathrm{Fe}_{80} \mathrm{Nb}_{6} \mathrm{~B}_{14}\right)_{0.88} \mathrm{Dy}_{0.12}$ alloys in zirconium is a complex problem. The $\mathrm{Zr}$ addition strongly affected the phase structure in the way that the formation of $\mathrm{Fe}-\mathrm{Zr}$ compounds was preferred, and for $x \geq 0.05$, the hard magnetic $\mathrm{Dy}_{2} \mathrm{Fe}_{14} \mathrm{~B}$ compound disappeared. This hard magnetic phase was replaced by $\mathrm{Fe}_{2} \mathrm{Zr}$ and even $\mathrm{Zr}_{3} \mathrm{Fe}$ for the alloy with $x=0.5$. The changes in the phase structure caused the observed appearance of crystalline Dy, it being a source of high magnetic moments at lower temperatures. In fact, this caused an interesting effect related to the magnetic state of Dy. At higher temperatures (above the Curie point of Dy), it was paramagnetic and uncoupled with the ferromagnetic $\mathrm{Fe}_{2} \mathrm{Zr}$ phase. Below this Curie point, one may expect the occurrence of the ferromagnetic exchange interaction between Dy atoms and antiferromagnetic coupling with Fe atoms in the interphase regions. In this situation, the magnetization processes are very complex because of the appearance of exchange interactions and exchange anisotropy. Finally, it is possible to "switch" on (or off) apparent coercivity and remanence of the $\mathrm{Fe}_{2} \mathrm{Zr}$ phase, which could be significant, for example, for sensor applications.

\section{Conclusions}

The aim of the presented work was to study structural and magnetic properties of the $\left(\mathrm{Fe}_{80} \mathrm{Nb}_{6} \mathrm{~B}_{14}\right)_{0.88} \mathrm{Dy}_{0.12}$ alloy diluted in non-magnetic $\mathrm{Zr}$. The impact of the $\mathrm{Zr}$ addition can be divided into two groups of alloys, i.e., for $x<0.05$ and for $x \geq 0.05$. For the first group, the phase structure did not significantly change and revealed the occurrence of the dominant hard magnetic $\mathrm{Dy}_{2} \mathrm{Fe}_{14} \mathrm{~B}$ compound as well as relatively soft $\mathrm{DyFe}_{2}$. However, it was shown that the observed fragmentation of the microstructure affected the magnetization processes of the examined alloys. The coercive field gradually decreased, while for $x=0.01$, weak increases in $M_{\mathrm{S}}$ and $M_{\mathrm{r}}$ were detected. For $x=0.05$, we observed a formation of needle-like micrometric grains of the mainly $\mathrm{Dy}_{2} \mathrm{Fe}_{17}$ phase. A further increase in $\mathrm{Zr}$ addition led to the increasing contribution of the Fe-Zr compounds and, simultaneously, the separation of crystalline Dy. In this range of the $x$ parameter (i.e., for $x=0.2$ and $x=0.3$ ), significant increases in $M_{\mathrm{s}}$ and $M_{\mathrm{r}}$ were observed. Additionally, at lower temperatures, the hysteresis loops revealed the appearance of magnetic anisotropy originating from the ferromagnetic state of Dy and some Dy-Fe coupling in the interphase regions.

Author Contributions: Conceptualization, G.Z., A.C.; methodology, G.Z., A.C., E.T., J.K., D.C.; validation, G.Z., A.C., E.T., J.K., D.C.; formal analysis, G.Z., A.C.; writing-original draft preparation, G.Z., A.C. All authors have read and agreed to the published version of the manuscript.

Funding: This research received no external funding.

Institutional Review Board Statement: Not applicable.

Informed Consent Statement: Not applicable.

Data Availability Statement: Data are available on request from the corresponding author.

Conflicts of Interest: The authors declare no conflict of interest.

\section{References}

1. Comstock, R.L. Review Modern magnetic materials in data storage. J. Mater. Sci. Mater. Electron. 2002, 13, 509-523. [CrossRef]

2. Gibbs, M.R.J.; Hill, E.W.; Wright, P.J. Magnetic materials for MEMS applications. J. Phys. D Appl. Phys. 2004, 37, R237. [CrossRef]

3. Gutfleisch, O.; Willard, M.A.; Brück, E.; Chen, C.H.; Sankar, S.G.; Liu, J.P. Magnetic Materials and Devices for the 21st Century: Stronger, Lighter, and More Energy Efficient. Adv. Mater. 2011, 23, 821-842. [CrossRef]

4. Coey, J.M.D. Perspective and Prospects for Rare Earth Permanent Magnets. Engineering 2020, 6, 119-131. [CrossRef]

5. Gutfleisch, O. Controlling the properties of high energy density permanent magnetic materials by different processing routes. $J$. Phys. D Appl. Phys. 2000, 33, 157-172. [CrossRef]

6. Rao, A.S. Alnico permanent magnets an overview. In Proceedings of the Electrical/Electronics Insulation Conference, Chicago, IL, USA, 4-7 October 1993; pp. 373-383.

7. Zhou, L.; Tang, W.T.; Ke, L.; Guo, W.; Poplawsky, J.D.; Anderson, I.E.; Kramer, M.J. Microstructural and magnetic property evolution with different heat-treatment conditions in an alnico alloy. Acta Mater. 2017, 133, 73-80. [CrossRef] 
8. Sagawa, M.; Fujimura, S.; Yamamoto, H.; Matsuura, Y.; Hiraga, K. Permanent magnet materials based on the rare earth-iron-boron tetragonal compounds. IEEE Trans. Magn. 1984, 20, 1584-1589. [CrossRef]

9. Manaf, A.; Buckley, R.A.; Davies, H.A. New nanocrystalline high-remanence Nd-Fe-B alloys by rapid solidification. J. Magn. Magn. Mater. 1993, 128, 302. [CrossRef]

10. Zhang, J.; Lim, K.Y.; Feng, Y.P.; Li, Y. Fe-Nd-B-based hard magnets from bulk amorphous precursor. Scr. Mater. 2007, 56, 943. [CrossRef]

11. Tao, S.; Ahmad, Z.; Zhang, P.; Yan, M.; Zheng, X.; Zhang, S.; Pang, N. High-coercivity Nd7.5Y2.7Fe62B22.3Nb3.1Cu2.4 nanocomposite magnet produced by rapid solidification proces. J. Alloys Compd. 2018, 735, 81. [CrossRef]

12. Randrianantoandro, N.; Crisan, A.D.; Crisan, O.; Marcin, J.; Kovac, J.; Hanko, J.; Grenèche, J.M.; Svec, P.; Chrobak, A.; Skorvanek, I. The influence of microstructure on magnetic properties of nanocrystalline $\mathrm{Fe}-\mathrm{Pt}-\mathrm{Nb}-\mathrm{B}$ permanent magnet ribbons. J. Appl. Phys. 2010, 108, 093910. [CrossRef]

13. Jiang, J.S.; Pearson, J.E.; Liu, Z.Y.; Kabius, B.; Trasobares, S.; Miller, D.J.; Bader, S.D. A new approach for improving exchangespring magnets. J. Appl. Phys. 2005, 97, 10K311. [CrossRef]

14. Efullerton, E.; Sjiang, J.; Dbaderb, S. Hard/soft magnetic heterostructures: Model exchange-spring magnets. J. Magn. Magn. Mater. 1999, 200, 392-404. [CrossRef]

15. Magnus, F.; Brooks-Bartlett, M.E.; Moubah, R.; Procter, R.A.; Andersson, G.; Hase, T.P.A.; Banks, S.T.; Hjörvarsson, B. Long-range magnetic interactions and proximity effects in an amorphous exchange-spring magnet. Nat. Commun. 2016, 7, ncomms11931. [CrossRef]

16. Thórarinsdóttir, K.A.; Hase, T.; Hjörvarsson, B.; Magnus, F. Amorphous exchange-spring magnets with crossed perpendicular and in-plane anisotropies. Phys. Rev. B 2021, 103, 014440. [CrossRef]

17. Chrobak, A.; Ziółkowski, G.; Szóstak, B. Optimization of hard magnetic properties of composites containing ultra-high coercive phases-Simulations. Phys. B Condens. Matter. 2019, 575, 1-7. [CrossRef]

18. Li, D.; Wang, F.; Xia, A.; Zhang, L.; Li, T.; Jin, C.; Liu, X. A facile way to realize exchange coupling interaction in hard/soft magnetic composites. J. Magn. Magn. Mater. 2016, 417, 355-358. [CrossRef]

19. Chrobak, A.; Zółkowski, G.; Randrianantoandro, N.; Klimontko, J.; Chrobak, D.; Prusik, K.; Rak, J. Ultra-high coercivity of (Fe86-xNbxB14)0.88Tb0.12 bulk nanocrystalline magnets. Acta Mater. 2015, 98, 318-326. [CrossRef]

20. Ziółkowski, G.; Chrobak, A.; Klimontko, J.; Chrobak, D.; Zivotsky, O.; Hendrych, A.; Rak, J. High coercivity in Fe-Nb-B-Dy bulk nanocrystalline magnets. Phys. Status Solidi A 2016, 213, 2954-2958. [CrossRef]

21. Ziółkowski, G.; Chrobak, A.; Klimontko, J.; Granek, K.; Chrobak, D. Effect of Tb/Y substitution on structural and magnetic properties of Fe-Nb-B-Tb type of high-coercive alloys. J. Alloys Compd. 2019, 784, 794-799. [CrossRef]

22. Chrobak, A.; Karolus, M.; Haneczok, G. Preparation of Fe-based bulk amorphous and nanocrystalline alloys by mould suction casting technique. Solid State Phenom. 2010, 163, 233-238. [CrossRef] 